\title{
Common gas phase molecules from fungi affect seed germination and plant health in Arabidopsis thaliana
}

\author{
Richard Hung $^{1 *}$, Samantha Lee ${ }^{1}$, Cesar Rodriguez-Saona ${ }^{2}$ and Joan W Bennett ${ }^{1}$
}

\begin{abstract}
Fungal volatile organic compounds (VOCs) play important ecophysiological roles in mediating inter-kingdom signaling with arthropods but less is known about their interactions with plants. In this study, Arabidopsis thaliana was used as a model in order to test the physiological effects of 23 common vapor-phase fungal VOCs that included alcohols, aldehydes, ketones, and other chemical classes. After exposure to a shared atmosphere with the 23 individual VOCs for $72 \mathrm{hrs}$, seeds were assayed for rate of germination and seedling formation; vegetative plants were assayed for fresh weight and chlorophyll concentration. All but five of the VOCs tested (1-decene, 2-n-heptylfuran, nonanal, geosmin and -limonene) had a significant effect in inhibiting either germination, seedling formation or both. Seedling formation was entirely inhibited by exposure to 1-octen-3-one, 2-ethylhexanal, 3-methylbutanal, and butanal. As assayed by a combination of fresh weight and chlorophyll concentration, 2-ethylhexanal had a negative impact on two-week-old vegetative plants. Three other compounds (1-octen-3-ol, 2-ethylhexanal, and 2-heptylfuran) decreased fresh weight alone. Most of the VOCs tested did not change the fresh weight or chlorophyll concentration of vegetative plants. In summary, when tested as single compounds, fungal VOCs affected $A$. thaliana in positive, negative or neutral ways.
\end{abstract}

Keywords: Volatile organic compound; Arabidopsis thaliana; Fungi; Seed germination; Chlorophyll concentration; Gas chromatography; Mass spectroscopy

\section{Introduction}

Volatiles organic compounds (VOCs) are low molecular mass compounds with high vapor pressure and low to medium water solubility that exist in the gaseous state at room temperature (Herrmann 2010). Approximately 250 VOCs have been identified from fungi (Chiron and Michelot 2005) as the products of both primary and secondary metabolism (Turner and Aldridge 1983; Korpi et al. 2009). These gas phase molecules are emitted in complex mixtures that vary quantitatively and qualitatively depending not only on the age and genetic profiles of the producing species but also on extrinsic variables such as substrate, temperature, moisture level and $\mathrm{pH}$ (Sunesson et al. 1995; Claeson et al. 2002; Matysik et al. 2008). Fungal volatiles have distinctive odorant properties and they have been studied extensively for their positive and

\footnotetext{
* Correspondence: Richard.Hung@rutgers.edu

'Department of Plant Biology and Pathology, Rutgers, The State University of New Jersey, 59 Dudley Rd., New Brunswick, NJ 08901, USA Full list of author information is available at the end of the article
}

negative sensory properties. They impart unique aromas and flavors to mold-ripened cheeses, Japanese koji and other mold-fermented food products (Steinkraus 1983; Kinderlerer 1989), and are responsible for the bouquet of gourmet mushrooms such as boletes, chanterelles and truffles (Cho et al. 2008; Fraatz and Zorn 2010). On the negative side, when foods are contaminated by molds, they produce off flavors. VOCs have been used as an indirect indicator of fungal spoilage in agricultural products (Borjesson et al. 1992; Jelen and Wasowicz 1998; Schnürer et al. 1999) and of mold contamination in water-damaged buildings (Kuske et al. 2005; Sahlberg et al. 2013). Finally, because VOCs can diffuse through the atmosphere and the soil, they are well adapted for signaling between species that share a common ecological niche. Both bacterial and fungal VOCs play competitive roles in chemical interactions between microorganisms (Beattie and Torrey 1986; Morath et al. 2012). Many plant and microbial volatile molecules function as semiochemicals, otherwise known as "infochemicals", and there is a large literature on the ability of fungal VOCs to mediate 
arthropod behavior, where they have properties as synomones, allomones, and kairomones (Rohlfs et al. 2005; Mburu et al. 2011; Davis et al. 2013). The fungal VOC commonly called "mushroom alcohol" (1-octen-3-ol) is responsible for much of the musty odor associated with mold contamination and is an important insect semiochemical. It attracts many insect species, including the malaria mosquito (Takken and Knols 1999; Thakeow et al. 2008).

In contrast, the interactions between fungal VOCs and plants have not received much scientific attention (Bitas et al. 2013). Based on the observation that there is very little vegetation in areas known to have truffles (subterranean gourmet fungi), it has been hypothesized that these fungi may have the ability to suppress plant growth through their volatiles (Splivallo et al. 2007). Kishimoto et al. (2007) have shown that 1-octen-3-ol enhances resistance of mature plants of Arabidopsis thaliana to Botrytis cinerea and activates some of the same defense genes turned on by ethylene and jasmonic acid signaling, important plant hormones involved in plant defense.

We hypothesized that we could distinguish between bioactive and inactive fungal vapors by using chemical standards of individual VOCs and then exposing plants to controlled concentrations in a model habitat. We selected A. thaliana as our test species due to the many benefits associated with the use of a well recognized model system including but not limited to: small size, short life cycle, genetic tractability, and comprehensively researched background. Preliminary studies have also shown that tomato plants exposed to VOCs are affected in a similar fashion to $A$. thaliana exposed to the same VOCs indicating that A. thaliana is a good model organism for study. Similarly, the effects of fungal VOCs on plant development have been demonstrated in several plants in Brassicaceae family including radish, cabbage, rape, and broccoli (Ogura et al. 2000). The aim of our study was to evaluate the effect of individual fungal VOCs on seed germination, vegetative plant growth and chlorophyll concentration in a controlled environment. In this report, our specific objectives have been to create standardized model exposure habitats in order to compare the possible stimulatory and inhibitory effects of fungal VOCs from different chemical classes (e.g., alcohols, aldehydes, ketones, and so forth) and to conduct exposure studies using $A$. thaliana seeds and two-week-old vegetative plants.

\section{Materials and methods}

\section{Plant material and seed preparation}

All volatile exposure tests were done with Arabidopsis thaliana ecotype Columbia 7. Surface-sterilization of seeds and seedling formation studies were conducted as described previously with slight modifications (Hung et al. 2013). Surface sterilized seeds were sown on Murashige and Skoog (MS) media with vitamins, 3\% sucrose, and 0.3\% Gellan Gum Powder (G 434 PhytoTechnology Laboratories, Shawnee Mission, KS). In germinationseedling formation studies, seeds were sown on Petri dishes (20 seeds per plate) with $20 \mathrm{ml}$ MS media and placed at $4^{\circ} \mathrm{C}$ in the dark for three days to stratify the seeds. Seeds used to grow plants for exposure assays of two-week old plants were sown individually in test tubes with $10 \mathrm{ml}$ of MS, covered with plant tissue culture caps and then stratified as described above. After three days, the stratified seeds in their individual test tubes were placed in a growth chamber at $21^{\circ} \mathrm{C} \pm 2{ }^{\circ} \mathrm{C}$ with a 16 hour photoperiod for two weeks prior to exposure to VOCs.

\section{Chemicals and exposure conditions}

Authentic standards of these high purity chemicals were purchased in liquid form from Sigma-Aldrich (St. Louis, Missouri). The criteria for the selection of these compounds were: 1) the volatiles should represent different chemical classes, 2) they had been isolated from a range of fungal species including both mushrooms and molds, and 3) that they included several VOCs commonly found in soils.

The germination and vegetative exposure to VOCs were determined using the methods described previously (Hung et al. 2014; Lee et al. 2014). Seeds (in Petri plates) or two-week-old plants (in individual test tubes) were exposed in one liter culture vessels (see Additional file 1). All tests were done at a low concentration similar to the concentration of VOCs analyzed previously: one part per million $(1 \mathrm{ppm}=1 \mu \mathrm{l} / \mathrm{l})$. The desired concentration of $1 \mathrm{ppm}$ in the test container was obtained by depositing a drop of the chemical standard (VOC) in liquid form onto the inside of the glass vessel. The compounds, due to their chemical properties will quickly volatilize into the gas phase in the test conditions. Before sealing the lids, a $10 \times 10 \mathrm{~cm}$ piece of Dura Seal Cling Sealing Film (Diversified Biotech) was placed over the top of each culture vessel so as to prevent VOC leakage through the polypropylene closure. The culture vessels containing either seeds in Petri plates or two-week-old plants in test tubes were arranged randomly in the growth chamber and then placed on a one inch throw rotator at $40 \mathrm{rpm}$ in order to volatilize and evenly distribute the compounds. The control plants were placed in identical conditions without any VOCs.

\section{Scoring germination stages}

The seeds were exposed to the individual VOCs for 72 hours and then examined under a binocular microscope where they were scored into three categories: no germination, germination (emergence of the radical [embryonic root]), and seedling formation (presence of the radicle, the hypocotyls and the cotyledons) (see Additional 
file 2). Seeds scored as "no germination" included seeds with a ruptured testa (seed coat) but without the presence of the radicle.

\section{Plant mass and chlorophyll concentration}

After exposure to the vapors of the individual VOCs, plants were removed from the test conditions, the shoot and leaves were cut away from the roots, and fresh weight of the shoots and leaves was obtained. The chlorophyll was extracted using the method of Jing et al. (2002) with some modifications. The plants were soaked overnight in $80 \%$ acetone at $4{ }^{\circ} \mathrm{C}$ in darkness prior to obtaining photometric readings at 663 and $645 \mathrm{~nm}$ with a spectrophotometer (DU800, Beckman Coulter, Brea, CA). Total chlorophyll $=20.2\left(\mathrm{~A}_{645}\right)+8.02\left(\mathrm{~A}_{663}\right)(\mathrm{V} / 1,000 * \mathrm{w})$ where $\mathrm{V}=$ total volume of the sample, $\mathrm{w}=$ weight of the sample, $\mathrm{A}_{663}=$ absorbance at $663 \mathrm{~nm}, \mathrm{~A}_{645}=$ absorbance at $645 \mathrm{~nm}$ (Palta 1990). Each solvent extract contained one plant per treatment.

\section{Statistical analysis}

The data were analyzed and plotted using Excel software (Microsoft, Redmond, WA) and SigmaPlot (SPSS Science Inc., IL). To test the significance of the exposure studies, one-way analysis of variance (ANOVA) and Student's t-tests were performed with the aggregated data. The Student's t-tests determine if there are significant differences between two sets of data: the control and VOC exposed plants. For germination exposures, two replicate plates with 20 seeds per plate were tested for each compound, with two independent experiments, for a total of 80 seeds. For vegetative plant exposure, four plants were placed in the exposure vessel and three jars were used for each experiment. There were three independent experiments for each compound, for a total of 36 plants.

\section{Results \\ Seedling formation tests}

The percentage of seeds germinating and progressing to seedling formation after exposure to the 23 fungal volatiles is shown in Figure 1 and summarized in Figure 2. In our experiments, more than $75 \%$ of control seeds progressed to the seedling stage after $72 \mathrm{hrs}$. Similar rates of seedling formation were observed for seeds exposed to 1decene, 2-n-heptylfuran, nonanal, geosmin and -limonene. In contrast, none of the seeds exposed to 2-ethylhexanal 1-octen-3-one, 3-methylbutanal, or butanal formed seedlings. Of these four inhibitory volatiles, radical protrusion (i.e. germination) was observed in only $19 \%$ of 1-octen-3one exposed seeds, while $83 \%$ of seeds exposed to butanal exhibited formation of a radical. Seeds exposed to the other 14 volatile compounds tested had intermediate levels of germination efficiency and seedling formation (Figure 2). Of the five aldehydes we tested, three (2-ethylhexanal, 3-methylbutanal, or butanal) inhibited seedling formation by $100 \%$ and one (3-methylproponal) inhibited seedling formation by $70 \%$. Nevertheless, no matter the extent of inhibition in the presence of the 23 VOCs tested, when removed from exposure to the VOCs after $72 \mathrm{hr}$, all seeds resumed germination and formed seedlings.

\section{Vegetative plants tests}

The fresh weight and chlorophyll concentration of control and exposed plants are given in Figure 3. The fresh weight of control plants was $22.4 \mathrm{mg}( \pm 6.7 \mathrm{SE})$. A significant decrease in fresh weight was observed after $72 \mathrm{hr}$ exposure to 1-octen-3-ol, 2-ethylhexanal, and 2heptylfuran, where the mean fresh weight was respectively $6.7 \mathrm{mg}( \pm 2.7 \mathrm{SE}), 11.2 \mathrm{mg}( \pm 4.9 \mathrm{SE})$, and $6.3 \mathrm{mg}( \pm 5.4 \mathrm{SE})$ less than controls. The other compounds tested $(( \pm) 2-$ methyl-1-butanol, geosmin, 2-methylpropan-1-ol, 1-octen3-ol, octan-1-ol, octan-3-ol, dec-1-ene, oct-1-ene, butanal, 2-ethylhexanal, 2-methylpropanal, 3-methylbutanal, nonanal, heptan-2-one, octan-2-one, oct-1-en-3-one, pentan-2one, isothiocyanatocyclohexane, octanoic acid, +limonene, -limonene, and 2-heptylfuran) did not cause significant differences in fresh weight of exposed vegetative plants (Figure 3).

In Figure 3, we have expressed the chlorophyll concentration data as $\mathrm{mg} / \mathrm{gm}$ of fresh weight of shoots and leaves. Five compounds (-2-methyl-1-butanol, 1-octen-3ol, dec-1-ene, heptan-2-one, and isothiocyanatocyclohexane) yielded statistically significant increases in chlorophyll concentration showing, respectively, $0.02 \mathrm{mg} / \mathrm{g}$, $0.2 \mathrm{mg} / \mathrm{g}, 0.18 \mathrm{mg} / \mathrm{g}, 0.02 \mathrm{mg} / \mathrm{g}$, and $0.4 \mathrm{mg} / \mathrm{g}$ greater amounts than controls. Three compounds, geosmin, 2ethylhexanal, and 1-octen-3-one caused a statistically significant decrease in chlorophyll concentration of, respectively, $0.15 \mathrm{mg} / \mathrm{g}, 0.35 \mathrm{mg} / \mathrm{g}$, and $0.42 \mathrm{mg} / \mathrm{g}$ less than controls. While geosmin did not adversely affect fresh weight, it did cause a significant decrease in chlorophyll concentration as indicated above. The compound 2-ethyl-hexanal decreased both fresh weight and chlorophyll concentration. The nonracemic form of -2-methyl-1-butanol showed a small but significantly different increase in both parameters.

In conclusion, all but five of the VOCs tested had a significant effect in inhibiting either germination, seedling formation or both. Three of the compounds (2-ethylhexanal, 1-octen-3-one, and 3-methylbutanal) showed more than $50 \%$ inhibition of seed germination, while 12 of the compounds (2-methylpropan-1-ol, 2-methylpropanal, heptan-2-one, octan-2-one, isothiocyanatocyclohexane, pentan-2-one, octan-3-ol, 1-octen-3-ol, 2-ethylhexanal, 1-octen-3-one, 3-methylbutanal, and butanal) were associated with more than a $50 \%$ retardation in seedling formation. Butanal was unusual in that $83 \%$ of seeds germinated (i.e. formed a radicle) but none of these germinated seeds progressed to seedling formation. In 


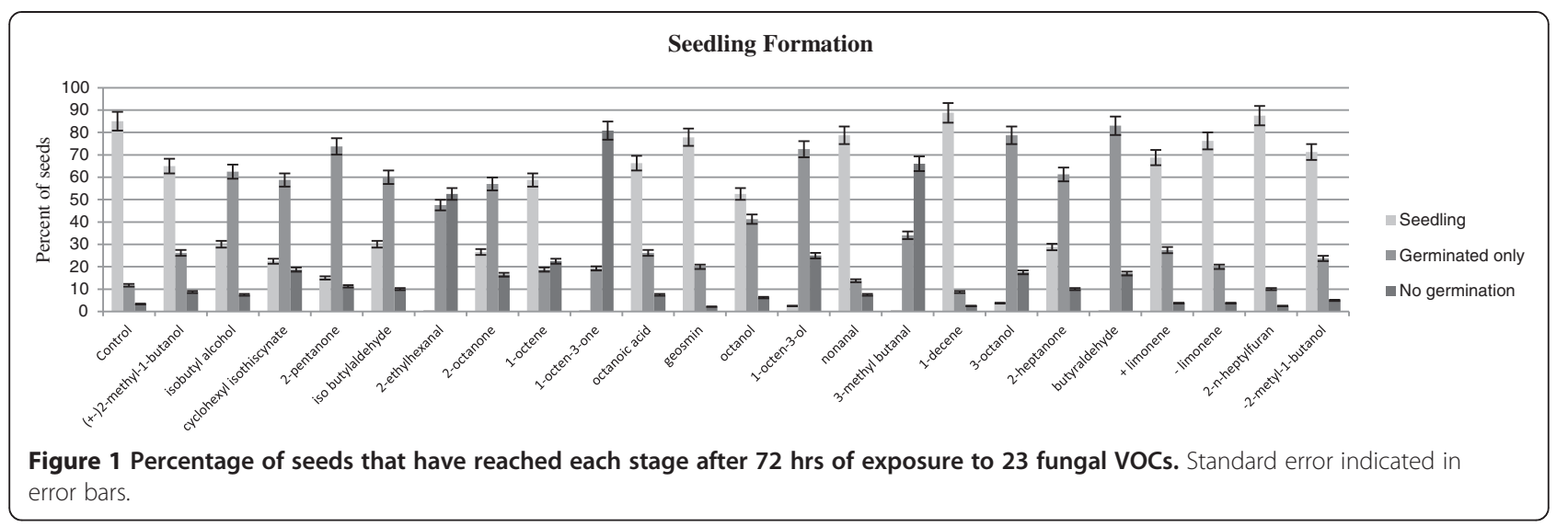

general, the most bioactive of the VOCs we tested were aldehydes and ketones. The single, most inhibitory VOC against germination and seedling formation was oct-1en-3-one, an eight carbon ketone that has been isolated from both molds and mushrooms (Jelen and Wasowicz 1998). Nevertheless, in all cases, VOC exposed seeds were able to resume germination and progress to seedling stage when removed from the shared atmosphere with the VOC. We conclude that the fungal VOCs we tested have a phytostatic (inhibitory), not a phytocidal (lethal) effect on seeds.

\section{Discussion}

In order to study the influence of individual fungal VOCs on plant health, we used A. thaliana as our test organism and developed standardized protocols for exposing seeds and young vegetative plants. We investigated a representative sample of common fungal VOCs encompassing seven alcohols, two alkenes, five aldehydes, four ketones, and a single representative isothiocyanate, carboxylic acid, and furan. In addition, we tested both isomers of the terpene 1-methyl-4-(1-methyetenyl)cyclohexene, commonly known as limonene. We used a

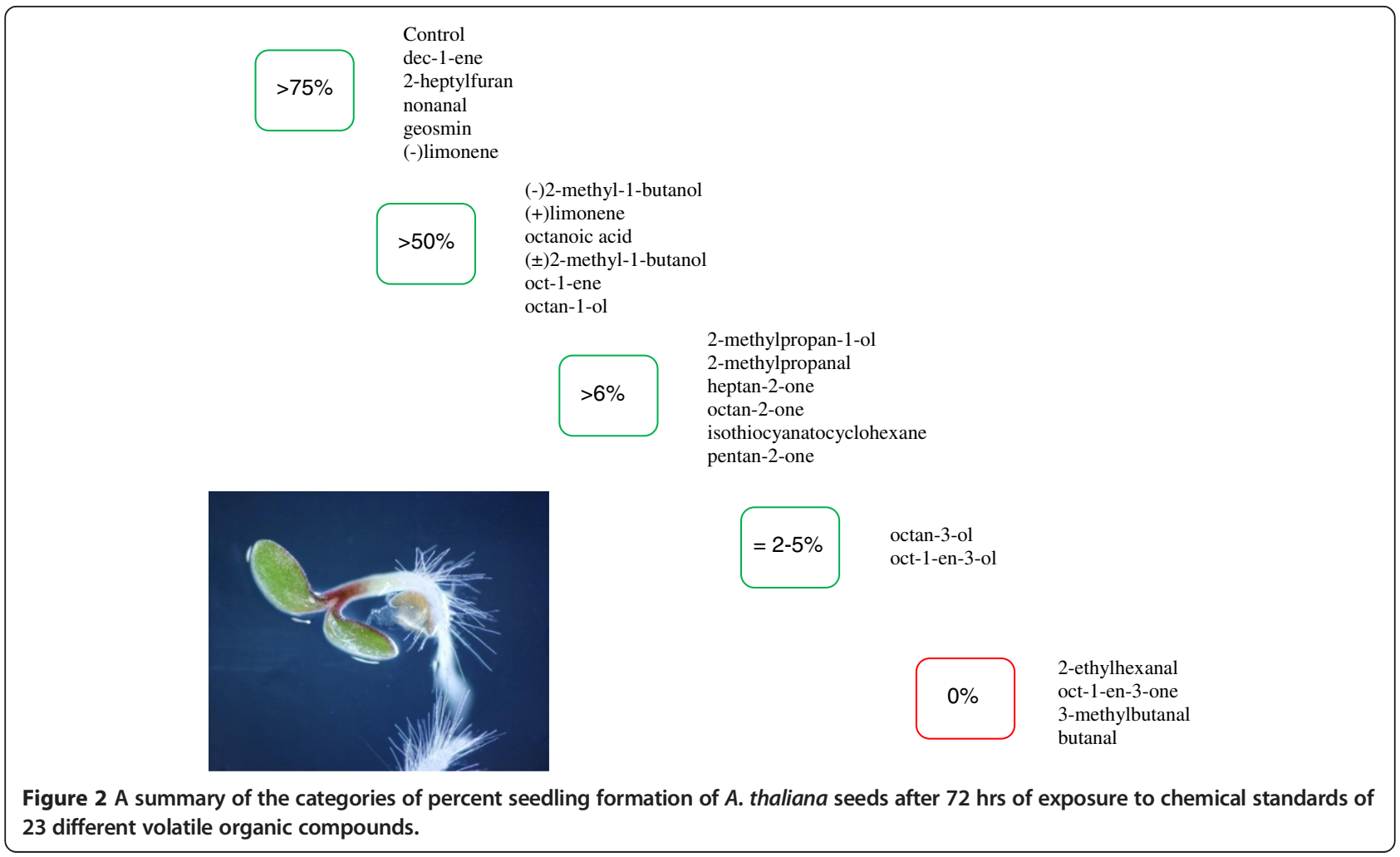




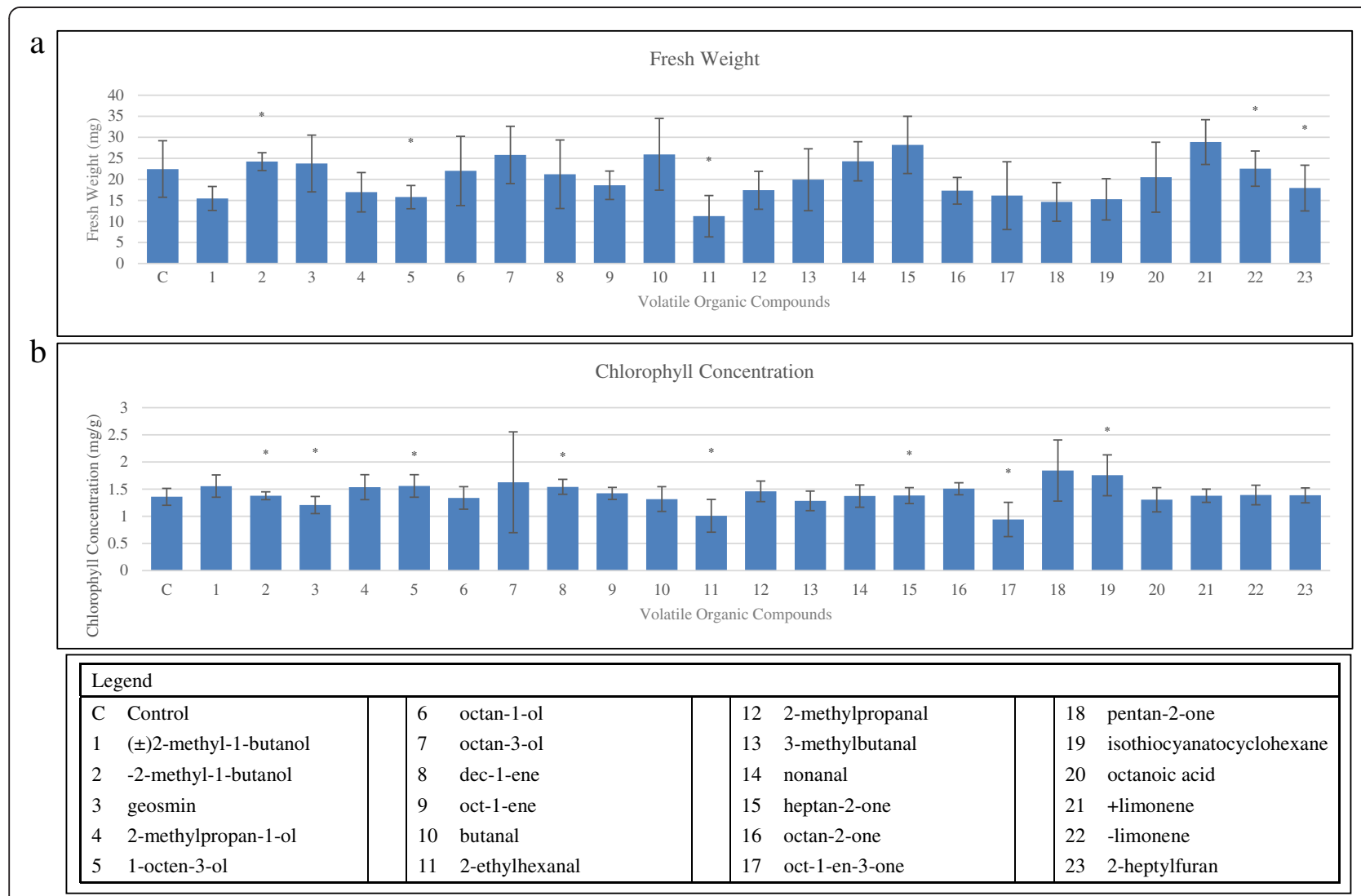

Figure 3 Fresh weight and chlorophyll concentration of two week old plants of $A$. thaliana exposed for 72 hrs to chemical standards of $\mathbf{2 3}$ different fungal volatile organic compounds. a. Fresh weight in $\mathrm{mg}$. b. Chlorophyll concentration in $\mathrm{mg} / \mathrm{g}$. Significant values compared to control are marked with an asterisk $p<0.04$. Standard error indicated in error bars.

72 hour exposure period, and exposed either seeds or young vegetative plants to $1 \mathrm{ppm}$ of chemical standards of the 23 fungal VOCs in a contained chamber.

Seed germination assays with lettuce, cucumber and other economically important species have been widely employed as low-cost, ethically acceptable toxicity tests to screen for dangerous levels of industrial contamination in water and soils (Banks and Schultz 2005; Wang et al. 2001). Almost all of these assay studies have involved aqueous phase compounds, although there have been a few scattered reports describing inhibitory effect of plant volatiles on the germination of seeds from crop and weed species (Holm 1972; Bradow and Connick 1990). The physiological basis for this inhibitory action has not been elucidated. A. thaliana, though not agriculturally important, offers a number of experimental advantages for studying basic aspects of plant biology, including seed germination, because of its many genetic resources (Koornneef et al. 2002). Our development of an $A$. thaliana exposure system for studying VOC effects under controlled conditions offers the promise of being able to use this species to dissect the germination inhibition response at the molecular level.
In contrast to seed germination studies, which all report inhibition of germination by VOCs (Holm 1972; French et al. 1975; Bradow and Connick 1990). To date, published studies of the effects of VOCs on vegetative plants report VOC-associated growth stimulation by mixtures of VOCs emitted by growing bacteria or fungi (Ryu et al. 2003; Minerdi et al. 2011; Hung et al. 2013; Paul and Park 2013). Many soil dwelling microbes emit VOCs that mediate various chemical "conversations" between the rhizosphere and plants (Wenke et al. 2010, 2012). For example, plant growth promoting rhizobacteria (PGPR) produce mixtures of VOCs that enhance growth in a wide variety of species (Farag et al. 2006; Vespermann et al. 2007; Lugtenberg and Kamilova 2009). In some cases, microbial VOCs induce systemic resistance (Van Loon et al. 1998; Ryu et al. 2003) or inhibit the growth of plant pathogens (Minerdi et al. 2009, 2011). Volatiles of Cladosporium cladosporioides enhance growth of tobacco plants (Paul and Park 2013) and our laboratory has shown that vegetative plants of $A$. thaliana seedlings grown in a shared atmosphere with volatiles emitted by living cultures of the biocontrol fungus Trichoderma viride, displayed increased size and vigor (Hung et al. 
2013). Fungal VOCs may contribute to the ability of certain species to outcompete neighboring plants. For example, the VOCs produced by Muscodor yucantanensis were toxic to the roots, and inhibited seed germination, of amaranth, tomato and barnyard grass (Macias-Rubalcava et al. 2010). In all of these cases, the growth-enhancing effects were mediated by mixtures of naturally emitted VOCs that change with both growth phase and extrinsic environmental parameters.

In our studies, we used a controlled system and exposed plants to low concentrations of individual VOCs. In this controlled habitat, the VOCs tested either had neutral or negative effects on vegetative plant growth, suggesting that the known growth enhancing effects of bacterial and fungal VOCs maybe by synergistic mixtures working in concert. A parallel example is provided by the antibiotic effects of volatiles produced by Muscodor albus. This species produces a mixture of VOCs that inhibit and kill a wide range of plant pathogenic fungi and bacteria (Strobel et al. 2001). Nevertheless, when Muscodor VOCs were tested individually, the inhibitory effects were not observed, suggesting that the antifungal activity required a suite of VOCs working in concert (Strobel et al. 2001).

It should be recognized that studies on transkingdom signalling mediated by fungal VOCs are technically difficult to conduct. Biogenic VOCs exhibit enormous heterogeneity chemically, spatially, and temporally; are found in low concentrations; and by definition have innate evaporative properties that make it difficult to investigate their impact on plant growth and development in natural settings. Our exploratory research shows that by using controlled concentrations of pure synthetic compounds in model habitats, individual VOCs can be studied one by one, thereby isolating their distinct growth-promoting, growth-inhibiting and other physiological effects. The genetic and genomic resources available for A. thaliana make this organism well suited for future research on the mechanistic basis of VOC mediated interactions and for analysis of the consequent biological responses. In summary, the study of gas phase fungal metabolites offers many interesting prospects for enlarging our understanding of the way in which fungi interact with plants in nature and may have potential for commercial application of VOCs in greenhouse agriculture.

\section{Additional files}

Additional file 1: Diagrams of exposure chambers for a. seeds in Petri dishes and $\mathrm{b}$. plants in test tubes.

Additional file 2: Representative images of stages of seedling formation A) No germination B) Germination, radical protrusion C) Seedling formation.

\section{Competing interests}

The authors declare that they have no competing interests.

\section{Authors' contributions}

$\mathrm{RH}$ designed the volatile exposure studies. In addition, he participated in the volatile exposure experiments and the drafting of the paper. SL participated in the exposure experiments and the drafting of the paper. CR-S collected and analyzed the volatile organic compounds. JWB conceived the study and participated in the drafting of the paper. All authors read and approved the final manuscript.

\section{Acknowledgements}

We thank Barbra Zilinskas, Chee-kok Chin, and Prakash Masurekar for their guidance and perspective. We also thank Elvira de Lange for helpful comments on an earlier draft of the manuscript. This research was supported by funds from Rutgers, The State University of New Jersey and National Science Foundation Graduate Research Fellowship under Grant No. 0937373 to SL.

\section{Author details}

'Department of Plant Biology and Pathology, Rutgers, The State University of New Jersey, 59 Dudley Rd., New Brunswick, NJ 08901, USA. ²Department of Entomology, Rutgers, The State University of New Jersey, 96 Lipman Drive, New Brunswick, NJ 08901, USA.

Received: 21 May 2014 Accepted: 5 June 2014

Published online: 15 July 2014

\section{References}

Banks MK, Schultz KE (2005) Comparison of plants for germination toxicity tests in petroleum-contaminated soils. Water Air Soil Pollut 167:211-219

Beattie SE, Torrey GS (1986) Toxicity of methanethiol produced by Brevibacterium linens toward Penicillium expansum. J Agr Food Sci 34:102-104

Bitas V, Kim H-S, Bennett J, Kang S (2013) Sniffing on microbes: diverse roles of microbial volatile organic compounds in plant health. Mol Plant Microbe Interact 26:835-843

Borjesson T, Stollman U, Schnurer J (1992) Volatile metabolites produced by six fungal species compared with other indicators of fungal growth on stored cereals. Appl Environ Microbiol 58:2599-2605

Bradow JM, Connick WJ (1990) Volatile seed germination inhibitors from plant residues. J Chem Ecol 16:645-666

Chiron N, Michelot D (2005) Odeurs de champignons: chimie et rôle dans les interactions biotiques- une revue. Cryptogam Mycol 26:299-364

Cho IH, Namgung H-J, Choi H-K, Kim YS (2008) Volatiles and key odorants in the pileus and stipe of pine-mushroom (Tricholoma matsutake Sing). Food Chem 106:71-76

Claeson AS, Levin JO, Blomquist G, Sunesson AL (2002) Volatile metabolites from microorganisms grown on humid building materials and synthetic media. J Environ Monit 4:667-672

Davis TS, Crippen TL, Hofstetter RW, Tomberlin JK (2013) Microbial volatile emissions as insect semiochemicals. J Chem Ecol 39:840-859

Farag MA, Ryu CM, Sumner LW, Paré PA (2006) GC-MS SPME profiling or rhizobacterial volatiles reveals prospective inducers of growth promotion and induced systemic resistance in plants. Phytochemistry 67:2262-2268

Fraatz MA, Zorn H (2010) Fungal Flavours. In: Hofrichter M (ed) The Mycota X: Industial Applications, 2nd edition. Springer-Verlag, Berlin, pp 249-264

French RC, Gale AW, Graham CL, Latterell FM, Schmitt CG, Marchetti MA, Rines HW (1975) Differences in germination response of spores of several species of rust and smut fungi to nonanal, 6-methyl-5-hepten-2-one, and related compounds. J Agric Food Chem 23:766-770

Herrmann A (2010) The chemistry and biology of volatiles. Wiley, Chichester

Holm RE (1972) Volatile metabolites controlling germination in buried weed seeds. Plant Physiol 30:293-297

Hung R, Lee S, Bennett JW (2013) The effect of low concentrations of the semiochemical 1-octen-3-ol on Arabidopsis thaliana. Fungal Ecol 6:19-26

Hung R, Lee S, Bennett JW (2014) The effects of low concentrations of the enantiomers of mushroom alcohol (1-octen-3-ol) on Arabidopsis thaliana. Mycology: Int J Fungal Biol 5:73-80

Jelen HH, Wasowicz E (1998) Volatile fungal metabolites and their relation to the spoilage of agricultural commodities. Food Rev Int 14:391-426

Jing H, Sturre MJG, Hille J, Dijkwel PP (2002) Arabidopsis onset of leaf death mutants identify a regulatory pathway controlling leaf senescence. Plant J 32:51-63

Kinderlerer J (1989) Volatile metabolites of filamentous fungi and their role in food flavor. J Appl Bacteriol Symp Suppl. 67:133S-144S 
Kishimoto K, Matsui K, Ozawa R, Takabayashi J (2007) Volatile 1-octen-3-ol induces a defensive response in Arabidopsis thaliana. J Gen Plant Pathol 73:35-37

Koornneef M, Bentsink L, Hilhorst H (2002) Seed dormancy and germination. Curr Opin Plant Biol 5:33-36

Korpi A, Jarnberg J, Pasanen A-L (2009) Microbial volatile organic compounds. Crit Rev Toxicol 39:139-193

Kuske M, Romain A-C, Nicolas J (2005) Microbial volatile organic compounds as indicators of fungi. Can an electronic nose detect fungi in indoor environments? Build Environ 40:824-831

Lee S, Hung R, Schink A, Mauro J, Bennett JW (2014) Phytotoxicity of volatile organic compound. Plant Grow Reg. doi:10.1007/s10725-014-9909-9

Lugtenberg B, Kamilova F (2009) Plant-growth-promoting rhizobacteria. Annu Rev Microbiol 63:541-556

Macias-Rubalcava ML, Hernandez-Bautista BE, Oropeza F, Duarte G, Gonzalez MC, Glenn AE, Hanlin RT, Anaya AL (2010) Allelochemical effects of volatile compounds and organic extracts from Muscodor yucatanensis, a tropical endophytic fungus from Bursera simaruba. J Chem Ecol 36:1122-1131

Matysik S, Herbarth O, Mueller A (2008) Determination of volatile metabolites originating from mould growth on wall paper and synthetic media. J Microbiol Methods 75:182-187

Mburu DM, Ndung'u MW, Maniania NK, Hassanali A (2011) Comparison of volatile blends and gene sequences of two isolates of Metarhizium anisopliae of different virulence and repellency toward the termite Macrotermes michaelseni. J Exp Biol 214:956-962

Minerdi D, Bossi S, Gullino ML, Garibaldi A (2009) Volatile organic compounds: a potential direct long-distance mechanism for antagonistic action of Fusarium oxysporum strain MSA 35. Environ Microbiol 11:844-854

Minerdi D, Bossi S, Maffei ME, Gullino ML, Garibaldi A (2011) Fusarium oxysporum and its bacterial consortium promote lettuce growth and expansin A5 gene expression through microbial volatile organic compound (MVOC) emission. FEMS Microbiol Ecol 76:342-351

Morath SU, Hung R, Bennett JW (2012) Fungal volatile organic compounds: a review with emphasis on their biotechnological potential. Fungal Biol Rev 26:73-83

Ogura T, Sunairi M, Nakajima M (2000) 2-Methylisoborneol and geosmin, the main sources of soil odor, inhibit the germination of Brassicaceae seeds. Soil Sci 46:217-227

Palta JP (1990) Leaf chlorophyll content. Remote Sens Rev 5:207-213

Paul D, Park KS (2013) Identification of volatiles produced by Cladosporium cladosporioides $\mathrm{CL}-1$, a fungal biocontrol agent that promotes plant growth. Sensors 13:13969-13977

Rohlfs M, Obmann BR, Petersen R (2005) Competition with filamentous fungi and its implication for a gregarious lifestyle in insects living on ephemeral resources. Ecol Entomol 30:556-563

Ryu C-M, Farag MA, Hu C-H, Reddy MS, Wei H-X, Paré PW, Kloepper JW (2003) Bacterial volatiles promote growth in Arabidopsis. Proc Natl Acad Sci U S A 100:4927-4932

Sahlberg B, Gunnbjörnsdottir M, Soonc A, Jogi R, Gislason T, Wieslander G, Janson C, Norback D (2013) Airborne molds and bacteria, microbial volatile organic compounds (MVOC), plasticizers and formaldehyde in dwellings in three North European cities in relation to sick building syndrome (SBS). Sci Total Environ 444:433-440

Schnürer J, Olsson J, Borjesson T (1999) Fungal volatiles as indicators of food and feeds spoilage. Fungal Genet Biol 27:209-217

Splivallo R, Novero M, Bertea CM, Bossi S, Bonfante P (2007) Truffle volatiles inhibit growth and induce an oxidative burst in Arabidopsis thaliana. New Phytol 175:17-24

Steinkraus KH (1983) Industrial Applications of Oriental Fungal Fermentations. In: Smith JE, Berry DR, Kristiansesn B (ed) The Filamentous Fungi Vol. 4 Fungal Technology. Edward Arnold, London, pp 171-189

Strobel GA, Dirkse E, Sears J, Markworth C (2001) Volatile antimicrobials from Muscodor albus, a novel endophytic fungus. Microbiology 147:2943-2950

Sunesson A-L, Vaes WHJ, Nilsson C-A, Blomquist GR, Andersson B, Carlson R (1995) Identification of volatile metabolites from five fungal species cultivated on two media. Appl Environ Microbiol 61:2911-2918

Takken W, Knols BG (1999) Odor-mediated behavior of Afrotropical malaria mosquitoes. Annu Rev Entomol 44:131-157

Thakeow P, Angeli S, Weißbecker B, Schütz S (2008) Antennal and behavioral responses of Cis boleti to fungal odor of Trametes gibbosa. Chem Senses 33:379-387

Turner WB, Aldridge DC (1983) Fungal Metabolites II. Academic Press, London
Van Loon LC, Bakker PAHM, Pieterse CMJ (1998) Systemic resistance induced by rhizosphere bacteria. Annu Rev Phytopathol 36:453-483

Vespermann A, Kai M, Piechulla B (2007) Rhizobacterial volatiles affect the growth of fungi and Arabidopsis thaliana. Appl Environ Microbiol 73:5639-5641

Wang X, Sun C, Gao S, Wang L, Shuokui H (2001) Validation of germination rate and root elongation as indicator to assess phytotoxicity with Cucumis sativus. Chemosphere 44:1711-1721

Wenke K, Kai M, Piechulla B (2010) Belowground volatiles facilitate interactions between plant roots and soil organisms. Planta 231:499-506

Wenke K, Weise T, Warnke R, Valverde C, Wanke D, Kai M, Piechulla B (2012) Bacterial Volatiles Mediating Information Between Bacteria and Plants. In: Witzany G, Baluska F (ed) Biocommunication of Plants. Springer-Verlag, Berlin, pp 327-347

doi:10.1186/s13568-014-0053-8

Cite this article as: Hung et al:: Common gas phase molecules from

fungi affect seed germination and plant health in Arabidopsis thaliana.

AMB Express 2014 4:53.

\section{Submit your manuscript to a SpringerOpen ${ }^{\odot}$ journal and benefit from:}

- Convenient online submission

- Rigorous peer review

- Immediate publication on acceptance

- Open access: articles freely available online

- High visibility within the field

- Retaining the copyright to your article

Submit your next manuscript at $>$ springeropen.com 